\title{
LOS NARRADORES \\ DE LA GENERACION DEL TREINTA: \\ EL GRUPO DE GUAYAQUIL
}

POR

ALFREDO PAREJA DIEZCANSECO
Quito, Ecuador

El hecho fortuito de ser quien escribe este artículo el sobreviviente de los cinco del Grupo de Guayaquil inicial, confiere una cierta credencial para expresar algunos aspectos fundamentales acerca de la significación que alcanzaran sus obras, así en la literatura ecuatoriana como en la hispanoamericana.

En el sentido de una asociación formal, el Grupo, desde luego, no existió. Empezó a ser llamado con su nombre ya histórico por Benjamín Carrión. Fue después conocido también como el Grupo de los Cinco. ¿Por qué la importancia de su significación? Creo que sólo puede responderse a esta pregunta si se analizan, por brevemente que fuere, las circunstancias sociales, económicas y políticas del Ecuador de los años treinta, muy semejantes, por cierto, a las que prevalecían en los otros países de la zona andina: Venezuela, Panamá, Colombia, Perú, Bolivia.

Procuremos hacerlo.

Independiente ya el Ecuador, el poder político y económico —-bajo la influencia del Imperio británico- pasó a manos de los criollos ricos, propietarios de tierras, y comerciantes exportadores, especialmente en Guayaquil. En pleno «crecimiento económico», como dicen los economistas, los grupos dominantes aprovecharon al máximo la explotación de mano de obra indígena, cada vez más pauperizada, por el sistema de hacienda: salarios irrisorios, cubiertos con aguardiente, alimentos, ropas y otros indispensables artículos, a precios mayores que los del incipiente mercado; y anticipos de moneda para que el «siervo» pudiese llegar a ser Prioste en alguna de las numerosas fiestas religiosas. Las deudas, de este modo, siempre crecieron y los créditos a favor del trabajador bajaron. Este era el 
llamado «concertaje» (concierto, acuerdo), cuyas consecuencias fueron la servidumbre transferida de padres a hijos, en un régimen que reconocía aún menos derechos que el feudalismo europeo antes de las revoluciones. francesa e industrial.

El concertaje, jurídicamente abolido desde la revolución alfarista, en 1895, continuó practicándose, con la persistencia de las instituciones sociales no escritas, hasta bien entrado el siglo Xx. Pues bien, de aquellos criollos latifundistas, por decirlo abreviadamente en términos generales, emanaría el partido conservador, y de los que proclamaron la reforma del statu quo, apendicularmente colonial, el partido liberal. Triunfante éste, las fuerzas del pasado fueron tan poderosas que apenas pudo lograrse la expropiación de los bienes de manos muertas (los latifundios de las órdenes religiosas) en 1908. En tanto, la industria textil de la sierra ecuatoriana se había arruinado con la competencia de los tejidos ingleses, importados en aras de la ideología liberal, y la clase exportadora de la costa, especialmente de Guayaquil, había prosperado inmensamente con las ventas al mundo del cacao, la milagrosa «pepa de oro».

Pero llegaron dos acontecimientos funestos: la primera ola depresionista consecutiva al final de la guerra de 1914-1918, que echó por tierra los precios del cacao, y una peste en las plantaciones, diagnosticada con el sardónico nombre de «escoba de la bruja», porque como debieron haberla montado en sus aquellarres quedaban las plantas.

El 15 de noviembre de 1922, una huelga general en Guayaquil, que inocentemente exigía mejor cambio monetario (la paridad era de poco más de dos sucres por un dólar) y mayores salarios, fue violentamente reprimida, con un saldo trágico de alrededor de mil quinientos muertos. Se ha estimado en una masa de treinta mil personas la manifestación en las calles de ese día (un tercio de la entonces población guayaquileña), lo cual alcanzaría un cinco por ciento catastrófico de muertos.

Los adolescentes y niños que integrarían el Grupo de Guayaquil contemplaron espantados la matanza de trabajadores. Es de suponer que, parcialmente cuando menos, aquel hecho sangriento y bárbaro influyese en el espíritu de la literatura ecuatoriana de los años treinta. El mayor de los cinco del grupo inicial, José de la Cuadra, tenía diecinueve años; Aguilera Malta y Pareja Diezcanseco, catorce; Gallegos Lara, once, y Gil Gilbert, apenas diez.

Para contar las influencias literarias nacionales sobre los escritores del Grupo de Guayaquil sobrarían los dedos de una mano: Juan Montalvo, por cierto, pero no su escritura, sino su alta y rebelde condición humana; 
cronológicamente, el primer novelista ecuatoriano es Juan León Mera, pero, para nosotros, no tuvo significación alguna su fiel y bien escrita imitación, algo grandilocuente, del Aiala de Chateaubriand, Cumandá (1879); de modo directo, un antecesor innegable, el ambateño Luis A. Martínez, con su magnífica novela costumbrista, afirmada en la tierra nuestra, A la costa (1904); Pancho Villamar, novela de realismo político, de Roberto Andrade, que leímos con retraso culpable (1900); los extraordinarios relatos humorísticos acerca de los montubios, de José Antonio Campos, publicados semanalmente en los diarios guayaquileños y recogidos en libro en 1929; la novela indigenista de Fernando Chaves, Plata y bronce (1927), sin duda alguna; dos cuentos de Leopoldo de Benites Vinueza, La mala hora y El enemigo, publicados en revistas hacia 1928; y me parece que nada más.

No sería, pues, excesivo decir que el Grupo de Guayaquil, así como todos los narradores que durante esos años surgieron en Quito, Cuenca y otras ciudades, vivieron en una orfandad literaria, en cuanto a precursores o maestros nacionales, que hubieran podido tradicionalmente continuarlos, con las naturales modificaciones de cada época sociocultural.

No es que no hubiese habido buena literatura en el Ecuador, especialmente en los años inmediatamente anteriores, sobre todo en poesía y prosa poética, modernista y postmodernista, sólo que se trataba de creaciones que realmente nada tenían en común con las situaciones y las circunstancias nacionales. Los poetas fueron brillantes (Medardo Angel Silva, Ernesto Noboa y Caamaño, Arturo Borja, Humberto Fierro, José María Egas, Hugo Mayo -éste, vanguardista-, Falconí Villagómez, Wenceslao Pareja), pero afrancesados, escapistas de una realidad que posiblemente les repugnaba. Raúl Andrade, en un ensayo magnífico, los llamó «una generación decapitada» (El perfil de la quimera, Quito, 1951).

Es menester recordar que al finalizar el decenio de los veinte ya la novela hispanoamericana había alcanzado frutos de verdad maduros, como La vorágine (1925), del colombiano José Eustasio Rivera; Don Segundo Sombra (1926), del argentino Ricardo Güiraldes; Los de abajo (1916), del mexicano Mariano Azuela; mucho antes, La trepadora (1925) y Doña Bárbara (1929), del venezolano Rómulo Gallegos. Ocurría que, a partir de la revolución mexicana, particularmente en el período 1910-1917, nuestros países habían empezado a tomar conciencia histórica de sí mismos. Esa toma de conciencia, descolonizadora de la inteligencia y el espíritu de quienes hacían literatura y empezaban a hacer una política nueva, hizo posible la generación de los escritores ecuatorianos de los treinta.

El 11 de octubre de 1930 apareció, en pobrísimo formato, un pequeño libro con ocho cuentos de cada uno, por Demetrio Aguilera Malta, Enrique 
Gil Gilbert y Joaquín Gallegos Lara. Demetrio y Joaquín tenían veintiún años; Enrique, apenas dieciocho. El título: Los que se van (cuentos del cholo y del montuvio); y este epígrafe: «Este libro no es un haz de egoísmos. Tiene tres autores: no tiene tres partes. Es una sola cosa... Pretende que unida sea la obra como fue unido el ensueño que la creó. Ha nacido de la marcha fraterna de nuestros tres espíritus. Nada más,» Luego, precedían la lectura unos versos de Joaquín, que terminaban así: «Los montuvios se van p'abajo del barranco,»

He de transcribir aquí lo que entonces dijo Benjamín Carrión, que hallábase en Francia:

... El primer cuento que comencé a leer era de Gallegos Lara... A las primeras líneas, el encuentro triunfal con la mala palabra, con el cruado decir popular, sin eufemismos... Todo eso salpimentado -como si fueran comas- de una cantidad apreciable de carajos y pendejos, orondos, impávidos, desvergonzados, que, de inmediato, como los desnudos de museo o los angelitos fálicos de los púlpitos barrocos, nos gritaban su inocencia. Luego, pasé a un cuento de Aguilera Malta: con un poco de lirismo escondido, y una aventurada y diáfana intención de poesía, pero también real, objetivo, másculo. Finalmente, me metí con Gil Gilbert: poderosa intensidad emocional, expresión directa, libre, con rudeza sana y viril... Por fin, me dije, entusiasmado. Por fin, podré también yo... hablar de la nueva literatura de mi Ecuador... Hablar de esta renacida esperanza... Procuré también que este milagro lo conocieran los amigos franceses: entusiasmó a Cassou, a Valery-Larbaud... Y a mí, que no tenía más parte que la del entusiasmo en el suceso, se me llamó le théoricien de la nueva tendencia ${ }^{1}$.

No fatigaré al lector con otras referencias de la crítica hispanoamericana sobre Los que se van. En general, fue sumamente favorable. Habíase abierto en el Ecuador una nueva época literaria, que se conocería como el realismo social. José de la Cuadra y quien escribe este artículo ya habíamos publicado algunas cosas, sobre todo De la Cuadra. Encontrábame yo en Nueva York. A mi retorno en 1931 quedó, de hecho, integrado el Grupo de Guayaquil por sus cinco primeros miembros.

Pero sí recordaré que, en 1945, el reputado traductor al francés de la literatura española e hispanoamericana contemporánea, Georges Pillement, publicó su Gens de l'Équateur, con versiones, entre otros autores ecuatorianos de la época, como Jorge Icaza y Humberto Salvador, de tres cuen-

'Benjamín Carrión, El nuevo relato ecuatoriano (Quito: Ed. Casa de la Cultura, 1958), p. 91. 
tos de José de la Cuadra, dos de Gallegos Lara, uno de Gil Gilbert, uno de Aguilera Malta y el segundo capítulo de mi novela El muelle.

A este núcleo inicial de los cinco se sumaron poco después narradores de tanta significación como Angel F. Rojas, Adalberto Ortiz y Pedro Jorge Vera. En 1936 se había ya constituido la Sociedad de Escritores y Artistas Independientes, virtualmente una extensión del Grupo de Guayaquil, con escritores como el ensayista y periodista Leopoldo Benites Vinueza, quien, en el servicio diplomático, llegaría a presidir la Asamblea de las Naciones Unidas; el historiador y poeta romancista Abel Romeo Castillo, Otón Guerra Castillo y otros; y notables artistas como el grabador y pintor Galo Galecio, el escultor Alfredo Palacio, los pintores Manuel Seminario Rendón, Segundo Espinel y Alba Calderón (esposa de Enrique Gil Gilbert), el arqueólogo Carlos Zevallos Menéndez, el historiador Francisco Huerta Rendón y algunos más que no recuerdo con exactitud.

De los cinco miembros iniciales del Grupo, De la Cuadra y Aguilera Malta fueron miembros del partido socialista, aunque Demetrio abandonó completamente la militancia; Gallegos Lara y Gil Gilbert se afiliarían al partido comunista y en él militarían hasta sus muertes; y quien escribe estos recuerdos, Pareja Diezcanseco, permanecería sin adherirse a partido político alguno, aunque sus ideas fueron siempre, como las de sus compañeros en la literatura y el arte, de lo que se dice izquierda o centroizquierda.

JosÉ DE LA CuADRA, nacido en Guayaquil el 3 de septiembre de 1903, fue el mayor de los cinco, no sólo en edad, sino en maestría del oficio de escribir, según me fue dado decirlo en el prólogo que escribí para la edición de sus obras completas ${ }^{2}$. Puedo agregar aquí que otro notable escritor, no reconocido entonces, por hallarse en la corriente del realismo social, fue Pablo Palacio, que solía escribir como Kafka antes de que fuese traducido al español o al francés.

Es admirable la capacidad de De la Cuadra para ajustar, ceñir las palabras a su valor semántico y simbólico, logrando así un estilo sobrio, de valores implícitos, especialmente en la que sin duda es su obra maestra, Los Sangurimas (Madrid, 1934).

${ }^{2}$ Alfredo Pareja Diezcanseco, prólogo a Obras completas de José de la Cuadra (Quito: Ed. Casa de la Cultura, 1958), pp. Ix y xxxIx. 
De la Cuadra escribió desde su adolescencia. Lo hacía en el diario $E l$ Telégrafo, sección folletín. Así apareció en 1923 «Nieta de libertadores», cuento en el que ya se advierten la garra y el espíritu del narrador de historias breves. Desde su libro Repisas (Guayaquil, 1931) es ya un dominador del oficio en el cuento. En Horno (Guayaquil, 1932) su maestría se ha entregado de lleno a la denuncia social, sin cartelismo propagandístico alguno; hay en este libro cuentos dignos de la más exigente antología, como «Banda del pueblo», «Cólimes Jótel» o «La tigra». Después de Los Sangurimas, citada antes, novela escrita a los treinta años de edad, retornó a los cuentos en Guasintón (Guayaquil, 1938), donde se agrupan catorce relatos. Los monos enloquecidos (Quito, 1951), novela póstuma inconclusa, es, como Los Sangurimas, precursora de lo que se llamó después realismo mágico. Hay ocho narraciones breves publicadas en diversas fechas y en medios de comunicación perecederos.

En la revista Semana Gráfica (Guayaquil, 1933 y 1934) publicó De la Cuadra 12 siluetas, trazos biográfico-críticos de dos poetas, seis escritores, un pianista, dos escultoras y un pintor, todos ellos, con excepción de uno, sus coetáneos. Se cuentan, además, ocho crónicas de diversa índole, numerosos artículos cortos y un ensayo notable: El montuvio ecuatoriano (Buenos Aires, 1937), profundo estudio de carácter sociológico acerca del poblador del interior de las zonas bajas tropicales, es decir, de los personajes de Los que se van y de los caracteres por él forjados en sus obras.

No gozaba De la Cuadra de un temperamento fácil. ¡Quién sabe qué trastornos interiores le atormentaron! Generoso muchas veces, violento a ratos, sabía cómo y cuándo ayudar a sus amigos, pero en ocasiones se comportaba como si algún fatídico dolor le corroyese los cimientos de su espíritu. Padeció gravemente; su médico y amigo le pidió cuidarse; no quiso hacerlo, y un 26 de febrero de 1941 dejó la envoltura física, poco después de haber cumplido sus treinta y siete años de edad. En sus funerales, a los que lamenté no asistir, pues vivía yo entonces en Buenos Aires, Enrique Gil Gilbert pronunció una frase feliz y entrañable: «iEramos cinco como un puño! ${ }^{3}$

Demetrio Agullera Malta, que también nació en Guayaquil un 24 de mayo de 1909, empezó a escribir muy joven, prosa poética en especial. En 1927 apareció Primavera interior, poemas, prosa de él, versos de Jorge Pérez Concha, quien luego se dedicaría a la biografía y al derecho

${ }^{3}$ Benjamín Carrión, op. cit., p. 91. 
internacional. En el mismo año, Demetrio es director artístico de la revista Voluntad, dirigida por Pérez Concha y Pareja Diezcanseco. En El libro de los mangleros (Guayaquil, 1929) aparece ya, en versos, el que sería su gran personaje novelístico, Don Goyo: «Don Goyito Quimí se ha muerto esta mañana... / Todos los cholos lloran en la casucha vieja... / Los perros ladran persiguiendo a una iguana / y en el estero mismo todo el mundo se queja.» Este pequeño libro es hoy una verdadera curiosidad bibliográfica: impreso en mimeógrafo y «con dibujos punáes del autor».

Como ya sabe el lector, en 1930 participa con ocho cuentos en la hoy clásica obra Los que se van. Su célebre novela Don Goyo, sin dejar de pertenecer al realismo social, es ya un anticipo del realismo mágico ${ }^{4}$, en las aventuras del cholo - habitantes de las zonas de los manglares que hunden sus retorcidas patas en el agua salobre- (Madrid, 1933). Viajero infatigable, Demetrio se establecería durante algún tiempo en Panamá, país sobre el cual escribiría una novela anti-imperialista, Canal Zone (Los Yanquis en Panamá) (Santiago de Chile, 1935). Poco después, en goce de una beca que le fue suprimida por otro de nuestros gobiernos de facto, se hallaría en Madrid, donde le sorprendió la carnicería de la guerra civil española, de la que publicaría un pequeño libro apresurado: Madrid, reportaje novelado de una resistencia heroica (Madrid, 1936). Su tercera novela, y muy celebrada, en la que prosigue con el tema simbólico-mítico iniciado en Don Goyo, es La isla virgen (Guayaquil, 1942).

Hombre increíblemente dinámico, su actividad creadora la dedicó también al teatro ${ }^{5}$ y a la cinematografía. Destacan en su dramaturgia $L a ́$ zaro (Guayaquil, 1941), No bastan los átomos y Dientes blancos (un volumen, Quito, 1955), y El tigre (Quito, 1956). Por esta bestia de tan hermosa estampa experimentaba Demetrio una fascinación, que es además una constante en la simbología de la montaña ectratoriana. En Chile, otra de las estaciones de su reiterado desplazamiento, y donde fue consejero cultural de la Embajada del Ecuador, siendo embajador Benjamín Carrión, escribió el libreto y dirigió la película La cadena infinita (1949). Luego, trasladado a Río de Janeiro, continuó con sus aventuras fílmicas, sin mayor éxito, y casó, en segundas nupcias, con la escritora mexicana Velia Márquez.

Radicado en la ciudad México, escribió la serie Episodios americanos: La caballeresa del sol (Madrid, 1964), Un nuevo mar para el rey y Los generales de Bolivar (Madrid, 1965). Cinco años más tarde aparecerá su

\footnotetext{
${ }^{4}$ Antonio Fama, Realismo mágico en la narrativa de Aguilera Malta (Madrid, 1977).

5 Gerardo Luzuriaga, Del realismo al expresionismo: el teatro de Aguilera Malta (Madrid, 1971).
} 
novela grande Siete lunas y siete serpientes (México, 1970), donde se reencuentra con sus antiguos mitos de la cholería costeña ecuatoriana ${ }^{6}$. Otros libros más publicó en México: El secuestro del general (1973), Jaguar (1977) y Réquiem para el diablo (1978). Sé, por su esposa, que trabajó hasta el día mismo de su muerte, acaecida en 1982, cuando acababa de dejar las funciones de embajador del Ecuador. No conozco, desafortunadamente, sus originales póstumos.

Quiera el lector excusarme por decirle que, muy enfermo, diabético, casi ciego, me escribió así:

Querido hermano Alfredo: Vela y yo estamos emocionados por cuanto me expresaste el $21 \ldots$ por teléfono. Fue algo tan inesperado y grato que hemos pasado algunas horas evocando los tiempos idos, en que nuestras ilusiones y obras estuvieron tan ligadas... Finalmente, al definirse más nuestras trayectorias..., continuamos manteniendo nuestra leal y fraterna amistad... (habíale yo solicitado, en nombre del Presidente de la República, que aceptase la Embajada nuestra ante el gogierno de México)... Supe que... te concedieron el Premio Espejo, verdaderamente consagratorio (Demetrio lo obtendría en 1981)... Me enteré de tus generosas referencias a tu viejo amigo y compañero...

En 1979, Aguilera Malta fue invitado por la Biblioteca del Congreso a Washington, a un simposio acerca de su obra total. Dos años más tarde, cuando yo recibiera una invitación análoga, recibí de él su fraterna congratulación, en noviembre de 1981. Faltaba ya muy poco para que se despojase de su existencia carnal, cuestión de semanas.

Joaquín Gallegos Lara, guayaquileño asimismo, vino a la vida un 9 de abril de 1909, con ambas piernas paralizadas por algún trastomo en el alumbramiento. Su madre, doña Enma, era una mujer abnegadísima, que supo cuidarlo y estimular su educación de autodidacta. La necesidad de valerse de sus brazos le desarrolló poderosos músculos en ellos y le amplió el tórax, de modo que, sentado, su figura era desproporcionada, de diminutas piernas, caja torácica ancha, cuello enhiesto y una cabeza con grandes orejas, de rasgos fuertes, en la que sobresalían sus ojos brillantísimos, iluminados con una profunda luz de ávida y generosa inteligencia.

- María E. Valverde, La narrativa de Aguilera Malta (Guayaquil: Casa de la Cultura, 1979). 
Cuando quien escribe este artículo lo conoció, hacia 1928 o 1929, Joaquín había por sí aprendido, por ejemplo, el francés y el italiano, que leía y hablaba con fluidez, aunque, obviamente, con fuerte acento. En el Grupo, Joaquín fue el gran incitador del movimiento literario de protesta social que nos impulsaba a escribir. Pensaba menos en él que en los demás, así como en toda causa justa que sirviera a los otros. Su cálida condición humana era ciertamente admirable. Solíamos reunirnos una vez a la semana, generalmente en la buhardilla de Joaquín, nosotros cuatro en sillas a su derredor, él en su hamaca o pasando de ella, casi por el aire, con sus fuertes manos tomadas de los tirantes hamaqueros, a su pequeño escritorio. Algunas veces las reuniones se hacían en casa de Pepe de la Cuadra y con no poca frecuencia en mi departamento, donde, desde 1934, año de mi matrimonio, nos brindaba el almuerzo mi mujer, Mercedes.

Nos leíamos lo que escribíamos. Nuestras críticas eran fuertes, francas, virilmente honestas. Recuerdo cómo «la censura» de ellos me llevó a cambiar párrafos enteros de mi novela El muelle. No había, pues, celos de artistas escritores, que son tan frecuentes, pues -y que se me perdonela vanidad del escritor, y del artista en general, no conoce límites sensatos a su egotismo narcisista, sobre todo cuando ha sido elogiado en exceso, que era nuestro caso en razón de la generosidad de Benjamín Carrión, Luis Alberto Sánchez, Ricardo Latcham y algún otro. En esos años, antes de 1940, ya correspondíamos con colegas de toda la América Latina, nuestros libros se editaban en Chile, la Argentina o España (en este último país, De la Cuadra y Aguilera Malta), y recibíamos visitas de escritores. como John Dos Passos, Thorton Wilder y José María Arguedas. Cuento un ejemplo: En un libro que me enviara Dos Passos desde Nueva York, me agregaba después de la dedicatoria y firma: "¡Qué bien escriben ustedes en Guayaquil!»

Joaquín escribía en varias publicaciones periódicas, relatos de él, críticas de libros recibidos, de manera especial de los ecuatorianos y de los movimientos literarios análogos al nuestro, que se desarrollaban en Quito, Cuenca o Manabí. En 1934 contrajo matrimonio con la escritora Nela Martínez, vivió un tiempo en Quito con un empleo en el Ministerio de Educación, del que fuera subsecretario Demetrio Aguilera Malta, y un año más tarde, en 1935, obtuvo el divorcio de Nela.

En 1946 publica su novela, largo tiempo demorada por él mismo, que era perfeccionista, o, dicho de otro modo, se exigía a sí mismo lo que no tanto a los demás; su novela, digo, Las cruces sobre el agua, basada en la matanza del 15 de noviembre de 1922, y en que a los abaleados en las orillas del río Guayas habíanles abierto el vientre con bayonetas para que 
que no reflotasen. La novela es muy hermosa, y es un documento indispensable.

Mi correspondencia personal con Gallegos Lara ha sido donada a la Biblioteca de la Casa de la Cultura Ecuatoriana. De las fotocopias que conservo, ofrezco esta muestra al lector, datada el 23 de diciembre de 1935 desde Quito:

Sólo ahora puedo enviarte nuestro doble abrazo de solidaridad por la enfermedad que aún no quiere dejar libre a tu pobre mujercita y de sincera alegría por la aparición de tu novela reciente (La Beldaca). Ya conoces mi opinión sobre este libro, cuando tuve el privilegio de leerlo en originales. Es un libro hermoso... Hazme el favor de enseñar la copia de mi artículo a Demetrio Aguilera...; enseñarás también el artículo a Gilbert y otros animales de igual condición... Los deseos de Nela, de mi madre y míos, son de que se mejore lo más breve... tu Mechita. Dale nuestro abrazo de cordialidad y ternura fraternal. Tu hermano, Joaco.

En otra, posterior, me habla de alguien, diciéndome: «... No me llama la atención, porque siempre ha sido un granuja», y se despide enviando «cariños a mi sobrina Cecilia», nombre de mi hija, entonces de un año de edad.

Poco después de la publicación de su Cruces sobre el agua enfermó gravemente de cáncer. Su madre y su tío médico, Julián Lara Calderón (era huérfano de padre), juntaron recursos para que pudiese viajar en busca de alivio a los Estados Unidos, pero era la época cómico-trágica del macartismo y le fue negada la visa. Me encontraba yo en Buenos Aires. Pedro Jorge Vera me escribió solicitándome una contribución para adquirir entre todos los amigos una silla de ruedas para Joaco. Pudo viajar a Lima, y retornó a Guayaquil, a morir, el 16 de noviembre de 1947, antes de llegar a los treinta y ocho años de edad.

En sus funerales, Vera declamó este poema escrito al compañero ausente:

Pero no hay llanto, pero no hay sonido

para tu verde corazón dormido,

para tu frente pura de arquitecto.

Para tu soledad irremediable

y para tu cadáver incansable

este adiós silencioso

adiós perfecto. 
Permítaseme reproducir parcialmente la "Carta a Joaquín», que escribí el 16 de noviembre de 1957 y publiqué en Letras del Ecuador, Casa de la Cultura, Quito, justamente a los diez años de su muerte:

Dicen que no es imposible comunicarse con las cosas que uno ama y que ya se han ido. Decir cosa es tal vez poco decir; pero, como significa todo lo que puede ser pensado, por eso la digo... En la inmensa distancia... inaccesible para mí, tú estás más completo, eres más universalmente tú, gracias a esa maravillosa distensión del tiempo y el espacio tan incomprensible para quienes todavía permanecemos en el lado individual de la vida... De parecida seguridad es la impresión que recibo al querer encontrarte para continuar nuestra vieja comunicación: verificar mejor tu existencia, comprobarla y conocerla como infinitamente más esencial y poderosa, por virtud de la ausencia de aquella forma que te hacía arrastrar las piernas, y te torturaba... Tí lo decías. No te gustaban los asuntos que bajaban demasiado, y, cuando así ocurría contra tu deseo, te ponías a vociferar palabras macizas e indignadas. ¿Te acuerdas? ... No lo sabía hace un instante, pero advierto que ya estoy comunicándome contigo... Y experimento una sensación entre el vértigo y la complacencia... pero que me da certeza de haber penetrado, por un resquicio, en el imponderable y verdadero mundo de los muertos. ... Y encontré al volver, desganado y suelto el río, el muelle flaco... Pero es mejor no recordarlo, porque el dolor, y tú lo sabes ahora, no sirve para nada, como no sea para que la maldad se harte... Cuando aún no he pronunciado bien la última palabra, te oigo reír anchamente, a la manera antigua, como cuando, a la cabecera de la mesa, el torso erguido, pequeñín y gritón, tú presidías esas comilonas de jóvenes dispuestos a tragarse el mundo entero. Has reído mucho, con jocundidad, 1lenándote de rojo la cara. Pues claro, iqué te va a importar el diminuto presente, en la distancia a que se ha colocado tu juicio con el beneficio de la muerte!... Pero... ha brotado, como un torrente, el desagrado que te causa la actualidad nuestra... aún no desprendida de tu corazón..., un desagrado que asume la forma más grave y acusadora, la del desprecio... Te comprendo, Joaquín. Y lo voy a contar a todos, publicando esta especie de coloquio de algo casi vivo con algo casi muerto. Porque tú te preocupabas mucho de la literatura, pero más por el hombre sin literatura. Y ni la una ni el otro han crecido bastante en los diez años que falta a tu espíritu la forma... Te gus: taba aconsejar en forma de que no se advirtiera el consejo. Eso te lo habías aprendido en los viejos diálogos socráticos, que reproducías montado en tu hamaca, con tus piernecitas colgando, la cabeza erecta, la voz clara, conclusiva, dirigiendo la polémica, indagando, indagando, siempre indagando, a las veces con una curiosidad aterradora... Pero la verdad es que esos profesionales mastuerzos de la palabra hueca han aprendido ya a regañadientes que tu literatura se sigue leyendo... Cuan. 
do tú me escribías aquí, me llamabas hermano. Dos tuve, contigo, que murieron. A los dos les escribo de vez en vez, como hoy.

Con posterioridad a la muerte de Gallegos Lara han sido publicados: Biografía del pueblo indio (Quito, 1952), un breve ensayo, cuya dedicatoria vale recordar: "A Ambrosio Lasso, Jefe indio. A Benjamín Carrión, nieto de españoles, autor de Atahuallpa»; Cuentos (Guayaquil, 1956); El Guaraguao y otros cuentos (Guayaquil, 1975), y La última erranza -todos los cuentos- (Quito, 1985). Joaquín dejó una novela inconclusa, Los Guandos, que ha completado y publicado su ex mujer, Nela Martínez (Quito, 1982).

Nadie más golpeado por la vida que este hombre de dolor..., nunca hombre más generoso... para expresar su juicio crítico, benévolo y justiciero a la vez; cuántas vocaciones jóvenes se lograron por haberse acercado a este noble maestro estimulante... Novela grande y gran novela a la par; tipificación certera y valiente de las clases sociales; poesía surgente de situaciones, paisajes, caracteres $y$, sobre todo, un gran calor de humanidad, una caudalosa ternura viril... Las calidades literarias de esta novela, su potencia expresiva, hacen de ella uno de los libros más recios y más bellos de nuestra actual literatura, dice de él, y de sus Cruces sobre el agua, Benjamín Carrión ?.

Enrique Gil Gilbert tenía apenas dieciocho años de edad (n. Guayaquil, julio 8 de 1912) cuando publicó sus ocho cuentos en Los que se van. Me apresuro a decir que mi relato preferido, de entre los veinticuatro de ese libro, hito inicial de la nueva literatura ecuatoriana, es «El malo», de Enrique. Fue acaso Gil Gilbert el escritor mejor dotado de los cinco primeros del Grupo: le venían las palabras como a los poetas el ritmo y la iluminación semántica, como a los hechiceros la magia. Su obra no es fecunda en cantidad, tal vez porque su vida interior fue tan rica que no requería de la expresión formal y limitadora de los sueños, quizá debido a su activa militancia política, colocada por él sobre cualquier otro menester humano, así fuera el artístico intemporal.

Yunga (Yunca en quechua: valle cálido), con una portada bellamente ilustrada por Aguilera Malta (Guayaquil, 1933), es el libro en que Enrique hace su segunda aparición a los lectores: son cinco cuentos de buena técnica y profunda poesía. A mi juicio, y de acuerdo con la opinión de

${ }^{7}$ Benjamín Carrión, op. cit., pp. 91-92. 
Angel F. Rojas ${ }^{8}$, el más hermoso y logrado de ellos es «El Negro Santander», un trabajador jamaicano del ferrocarril Guayaquil-Quito, de los que trajeron para volar con dinamita las rocas de la famosa «nariz del diablo» y poder colocar los rieles al filo de la montaña; la narración es suficientemente extensa y de peripecia múltiple como para llamarse una novela corta, una nouvelle, o novelina, como se quiera decir.

Un año después, en 1934, Enrique casa con una bella y talentosa pintora, Alba Calderón, de quien diría, en la dedicatoria de Nuestro pan, luego de ofrecer la novela a «los arroceros», «a mi madre, mi hermano y mi hijo...», a quien "me acompañó en la escritura de este libro con el mismo entusiasmo que me acompañó a vivir». Agregaría yo que Alba es, de modo no aritmético, una todavía hermosa sobreviviente del Grupo de los Cinco.

Después de algunos años de silencio fue publicada Emmanuel (Guayaquil, 1939), breve novela de una prosa riquísima, llena de intimismo poético trascendental. La narración seduce al lector desde el comienzo:

Emmanuel es hermano mío. No se me parece absolutamente en nada. Es alto, ancho; su pelo tiene el color de la tierra rojiza de arriba, donde los ríos recién vienen tiernos. Sus ojos verdes... No recturdo haber visto ojos así... Emmanuel ya no deja ver la luz de las palabras en sus ojos; $y$, sin embargo, su palabra no es muerta.

En 1941 Gil Gilbert gana con Nuestro pan (Guayaquil, 1942) el primer premio de un concurso nacional de novela, previo al internacional, convocado por la editorial norteamericana Farrar and Reinhart, en el cual obtuvo el primero Ciro Alegría con El mundo es ancho y ajeno y el segundo Enrique. Nuestro pan es la gran novela del arroz y los sembradores arroceros, explotados sin misericordia. El montuvio arrocero es un personaje tradicional del campo costeño del Ecuador, que ha llenado con sus cantares, conocidos con el romántico nombre de «amorfinos», y sus leyendas de aparecidos espectrales muchas hermosas páginas de nuestra literatura. Un epígrafe, de un decir popular, precede a la lectura del libro: «En habiendo arroz / aunque no haya Dios.»

De esta novela expresa Fernando Alegría: «... escrita en un lenguaje de auténtica jerarquía artística, apasionante en su desarrollo... La ternura, un claro sentido poético y una visión humanitaria de los problemas de su tierra, le permiten salvar los escollos acostumbrados en la novela social y regionalista, y alcanzar una resonancia universal» ${ }^{9}$. Y Benjamín Carrión:

8 Angel F. Rojas, La novela ecuatoriana (México, D. F., 1948), p. 190.

- Fernando Alegría, Breve historia de la novela hispanoamericana (México, 1959), pp. 250-251. 
« ¿Qué viada de novela para ser cosa cierta y grande!... Es, sin duda, la gran novela de la vida campesina de la tierra baja. Pero se siente una distonía al final, un cierto acomodo del escritor al militante político... Nuestro pan es, sin adjetivos innecesarios, una gran novela» ${ }^{10}$.

En 1944 Gil Gilbert es diputado a la Asamblea Constituyente y uno de los miembros fundadores de la Casa de la Cultura Ecuatoriana. Varios años transcurren, en los cuales está entregado a la tarea política de manera total, hasta que en 1967 da a publicidad un pequeño libro de cuentos, con el título del último de ellos: La cabeza de un niño en un tacho de basura (Guayaquil), con varios relatos menos afortunados que sus anteriores, salvo los reeditados en esta obra. Probablemente, me atrevo a suponer, la inmediatez de la tarea política, noble, transparentemente ética que siempre inspiró sus actos, impiđió a tan notable escritor continuar produciendo los trabajos que su admirable madurez hubiese logrado.

Enrique Gil Gilbert murió un 21 de febrero de 1973, en su nativa Guayaquil, poco después de haber cumplido los sesenta años.

Alfredo Pareja Diezcanseco: no me queda otro recurso que octparme ahora de mí mismo. Pero, eso sí, es obvio que no pueda ni deba. emitir juicio alguno de valor. Nací un 12 de octubre de 1908, guayaquileño, como mis cuatro compañeros del Grupo de los Cinco. Y honestamente puedo afirmar al lector que, con muy raras excepciones, nunca me he sentido ni medianamente satisfecho con mis obras publicadas, por manera especial de las aparecidas antes de 1933, es decir, hasta la edición de $E l$ muelle, novela acogida con beneplácito por la crítica hispanoamericana. He dicho ya en este artículo que Georges Pillement tradujo en 1945 un capítulo de esta novela, y ahora traduzco unas palabras de lo que expresa en el prefacio de esa obra: «No se ven en El muelle las escenas indignantes de las novelas de Icaza, sino sólo las miserias de un país, en el cual los trabajadores están sometidos a la voluntad del patrón. María del Socorro ... dulce y paciente personaje similar a las más conmovedoras heroínas de nuestra literatura proletaria» ${ }^{11}$.

He publicado trece novelas (dicen que son catorce, pero la tomada como segunda es apenas un reportaje novelado bastante reprochable), entre 1929 y 1974, cuyos títulos son: La casa de los locos, Río arriba, El

${ }^{10}$ Benjamín Carrión, op. cit., p. 99.

${ }^{11}$ Georges Pillement, Gens de l'Équateur (Paris: Éd. Pierre Seghers, 1945), pp. 9-10 y $141-165$. 
mueile, La Beldaca, Baldomera, Don Balón de Baba, Hombres sin tiempo, Las tres ratas, La advertencia, El aire y los recuerdos, Los poderes omnímodos, Las pequeñas estaturas, La Manticora.

Asimismo soy autor de dos biografías, cinco ensayos y ocho obras sobre la historia del Ecuador. En remotos años de juventud escribí versos, como casi todo principiante de escritor, pero tuve el acierto de conocerlos por malo y darlos al fuego. Ensayé también, y fracasé en ello, el cuento: sólo hubo uno publicable y publicado.

Como todos los que hacíamos literatura en el Ecuador de aquellos años, para ganar de vivir desempeñé numerosísimos oficios, desde mozo de restaurante en Nueva York, comerciante, visitador médico, profesor de enseñanza secundaria y universitaria, diplomático a ratos, hasta ministro de Relaciones Exteriores y embajador del Ecuador en Francia. Pero escribir ha sido, y sigue siendo, la pasión fundamental de mi espíritu, por razones que traté de expresar en 1985 al diario Libération de París:

... escribo para no sentir el naufragio de mi identidad personal, para impedir que las cosas exteriores me dominen; no para saber algo, sino para convencerme de que la existencia humana es una tarea para los otros, y que es menester trascenderla, no obstante la pavorosa limitación del lenguaje escrito... Escribo..., por una especie de encantamiento, de mágica razón incomprensible, iluminada, sin embargo, por el multiloquio del común, por los que están fuera de mi pequeño yo personal, por aquellos que nombran las cosas y deciden su uso, sin aprovecharlas, por aquellos que transformarán algún día el universo de miseria y guerra diabólica que nos ha sido dado vivir. Escribo por incertidumbre y por temor a mi soledad. Escribo para que las cosas no me subyuguen con su implícita mudez, y porque esa mi incertidumbre ha sido fabricada por un pasado que requiere, necesariamente requiere de la muerte. Escribo por anhelo de trascender mi época, para que la próxima sea menos injusta y mentirosa, menos cínica y opresora. Escribo, en fin, con la convicción de que el espíritu ha de lograr, cuando menos en el reducido espacio geográfico de mi personal y ya vieja existencia, una serena y plena soberanía, la necesaria soberanía para que la artera distribución de los bienes materiales sea subordinada a una pródiga distribución de bienes espirituales ${ }^{12}$.

* * * *

Angel Felicísimo Rojas es un novelista y ensayista de muy parca producción y de una sobria elegancia de lenguaje. Me he referido ya a su

${ }^{12}$ Libération: Pourquoi écrivez vous? (400 écrivains respondent - Des grandes signatures venues du monde entière) (Paris: N. Hors Series, Mars 1985), p. 42. 
estudio sobre La novela ecuatoriana, de 1948, y diré ahora que este lojano de nacimiento (diciembre 29, 1909) publicó Banca, su primera -así llamada por él- novela escolar, en 1933; un libro de cuentos, de exigente factura, Un idilio bobo (Guayaquil, 1949); una extraordinaria novela, que responde fácilmente a la más rigurosa exigencia, El éxodo de Yangana (Buenos Aires, 1949), cuyo personaje fundamental es un pueblo entero; y otra novela, anunciada y mantenida inédita por muchos años, acerca de una mina aurifera, Curipamba (Guayaquil, 1985), que no alcanza a remozar el realismo de los primeros años del Grupo.

Adalberto Ortiz (n. Esmeraldas, febrero 9, 1914), profesor normalista avecindado en Guayaquil, colaborador del diario El Telégrafo de esta ciudad, gana el primer premio en el Concurso de la Novela Ecuatoriana en 1942, con una novela admirable, Juyungo (Historia de un negro, una isla y otros negros), que le otorga inmediatamente prestigio hispanoamericano indiscutible. De ella dice Edmundo Ribadeneira:

Quien le da a la literatura ecuatoriana la primera novela del negro... una verdad que antes de él había permanecido inédita en el campo de nuestro relato: la del negro esmeraldeño en su choque contra la explotación y frente a la selva... Poéticamente rica..., humana y cálida. Todos sus personajes son tomados de la realidad ${ }^{13}$.

Poco después publicará en México (1945) un libro de poemas negros y mulatos (Adalberto es mulato con orgullo de serlo), Tierra, son y tambor, con un prólogo de Joaquín Gallegos Lara y grabados de Galo Galecio. En ese mismo año aparecen, también en México, su extenso cuentonovelina Los contrabandistas, con prólogo de José Antonio Portuondo y viñetas del autor (he de advertir que Adalberto es también un artista plástico de valía), y los poemas de Camino y puerto de la angustia, con prólogo de quien escribe este artículo, y en la editora La Isla - vale mencionarlo-, que dirigía entonces en México el poeta español Manuel Altolaguirre.

Adalberto Ortiz continúa escribiendo. En 1970, por ejemplo, su novela, de técnica renovada, El espejo y la ventana aparece en Guayaquil. Importa mencionar, entre su vasta producción, un breve ensayo, $L a$ negritud en la cultura latinoamericana y ecuatoriana (Quito, 1975). Y, por cierto, su «novela coral y colérica» La envoltura del sueño (Guayaquil, 1982), a la cual su prologuista, Hernán Rodríguez Castelo, llama una «gran empresa lingüística». Esta novela obtuvo una muy honrosa mención

${ }^{13}$ Edmundo Ribadeneira, La moderna novela ecuatoriana (Quito, 1981), pp. 120121. 
en un concurso convocado por la Editorial Novaro y la Asociación de Escritores de México.

Pedro Jorge Vera, guayaquileño, nacido el 16 de junio de 1914 , es otro de los miembros más conspicuos del Grupo de Guayaquil, que prosigue con éxito su obra de novelista, dramaturgo, poeta y periodista, no enturbiada en absoluto por su militancia política radicalmente izquierdista. Casado con una escritora de valiosos méritos, Eugenia Viteri, Vera es, con justísimos títulos, un escritor profesional. De su novela Los animales puros (Buenos Aires, 1946), Edmundo Ribadeneira dice: «Constituye un valioso aporte al desenvolvimiento y superación de nuestra novela nueva... De más está afirmar que ... está muy bien escrita y estructurada, y que es obra de un escritor de vocaciones artísticas sólidas...» ${ }^{14}$. Agrego que esa novela es uno de los primeros exitosos empeños por superar la narrativa excesivamente objetivada del realismo social de los años treinta. La opinión de Benjamín Carrión conviene también ser reproducida: «Los animales puros... no es ya la novela de aliento primitivo a que nos habían acostumbrado... Es novela con lectura y escritura... Una novela intelectualizada... Además del poder introspectivo y de la clara médula intelectual... tiene trance, tiene inspiración poética...» ${ }^{15}$.

La obra de Pedro Jorge Vera es vasta. Creo que su mejor acierto como novelista, además de la que se acaba de citar, es Las familias y los años (Madrid, 1982). Pero es menester recordar relatos como La Guamoteña (México, 1947); cuatro obras de teatro, en un volumen, Teatro (Quito, 1956): La mano de Dios, Luto eterno (es la pieza de mi preferencia), Los ardientes caminos y El dios de la selva. Y en poesía, Túnel iluminado (Quito, 1949).

El Grupo de Guayaquil --igual que los escritores de otras zonas del Ecuador en los años treinta- señaló, no haya duda, un hito importante en la literatura hispanoamericana. Si en el Ecuador de hoy se sabe, con Unamuno, que «lo bello es lo superfluo; lo que tiene su fin en sí», también se conoce y adhiere a lo que reza el escudo de Salamanca: "Quod natura non dat, Salmantica non praestat». Quiero decir con lo dicho que los escritores ecuatorianos de nuestros días están mejor dotados que los que tan ardientemente «militamos» en la generación de hace media centuria.

Quito, enero 1987.

\footnotetext{
${ }^{14}$ Ibíd., pp. 131-132.

${ }^{15}$ Benjamín Carrión, op. cit., pp. 202-203.
} 
